\title{
The Old-Boy Network and the Quality of Entrepreneurs
}

\author{
Mehmet Bac \\ Eren Inci
}

CESIFO WORKING PAPER NO. 3071

CATEGORY 11: INDUSTRIAL ORGANISATION

JUNE 2010

An electronic version of the paper may be downloaded

- from the SSRN website:

- from the RePEc website:

- from the CESifo website:

www.SSRN.com

www.RePEc.org

www.CESifo-group.org/wp 


\title{
The Old-Boy Network and the Quality of Entrepreneurs
}

\begin{abstract}
We study a model of network formation and start-up financing with endogenous entrepreneurial type distribution. A hub firm admits members to its network based on signals about entrepreneurs' types. Network membership is observable, which allows lenders to offer different interest rates to network and stand-alone entrepreneurs. We show that a network outcome can display a smaller number of high-type entrepreneurs even though the network is neither nepotistic nor informationally disadvantaged. While a welfare-improving network can emerge as a technically stable or unstable equilibrium, one that decreases welfare is always formed by a technically unstable equilibrium. However, the adverse welfare effects of a network and its corresponding type configuration may persist because ex-post high type entrepreneurs prefer to stay high type whereas those who wish to become high-type may need some time to react.
\end{abstract}

JEL-Code: D82, D85, L26.

Keywords: entrepreneur, network, start-up financing.

\author{
Mehmet Bac \\ Sabanci University \\ Orhanli / Tuzla \\ 34956 Istanbul \\ Turkey \\ bac@sabanciuniv.edu
}

\author{
Eren Inci \\ Sabanci University \\ Orhanli / Tuzla \\ 34956 Istanbul \\ Turkey \\ ereninci@sabanciuniv.edu
}

24 May 2010

The authors would like to thank Richard Arnott, Jing-Yuan Chiou, Toker Doganoglu, Firat Inceoglu, the participants at the 64th European Meeting of the Econometric Society, 2009 Annual Meeting of ASSET, and Ifo / CESifo \& ACES Conference on Banking and Institutions, especially the discussant Katharina Eck, and seminar participants at METU and IMT-Lucca for helpful comments. Inci acknowledges CESifo sponsorship for his conference presentation. 


\section{Introduction}

An informal information network, or an "old-boy" club, is a group of expert agents whose opinions on some individuals are informative. This kind of service is valuable in particular in the labor market and business relations: it is common practice for firms to solicit reference letters from job applicants, banks to consult experts and inspect their clients' credit records and relations. Membership or a positive reference from networks has signal value to the extent that networks perform screening and care about their reputations. There are countless benefits of informal networks to their members and the outside parties who interact with them. A branch in the labor economics literature avows the advantages of networks in the hiring and job search processes. ${ }^{1}$ There is also an entrenched literature in entrepreneurship stressing the advantages of networks for newly established firms. ${ }^{2}$ Harmful cases are mostly confined to nepotistic and/or informationally disadvantaged networks. ${ }^{3}$

This paper studies the effects of potential membership to an information network on entrepreneurs' efforts to improve their projects (i.e., upgrade their types). In our model, the network is meritocratic and has informational advantage over the market, and network entrepreneurs in equilibrium are more successful on average than stand-alone entrepreneurs, which is-as stated in Bruderl and Preisendorfer (1998)-one of the robust observations of the "network approach to entrepreneurship" initiated

\footnotetext{
${ }^{1}$ See, for example, Cahuc and Fontaine (2009), Calvo-Armengol and Jackson (2004, 2007), CalvoArmengol and Zenou (2005), Fontaine (2007), Granovetter (1974), Holzer (1988), Kugler (2003), Montgomery (1991), Mortensen and Vishwanath (1995), Munshi (2003), Rees (1966), Saloner (1985), Simon and Warner (1992), Taylor (2000), and Wabha and Zenou (2005). See Ioannides and Loury (2004) for a survey of the literature on the role of social networks in the labor markets.

${ }^{2}$ See, for example, Aldrich and Kim (2007), Aldrich, Rosen, and Woodward (1987), Aldrich and Zimmer (1986), Birley (1985), Bruderl and Preisendorfer (1998), Dubini and Aldrich (1991), Inci (2008), Parker (2008), and Uzzi (1996).

${ }^{3}$ See, for example, Lentz and Laband (1989) for favoritism in the admissions of children of doctors to medical schools. In such cases, merit-based and/or efficient allocation of individuals to the network is not guaranteed.
} 
by Aldrich and Zimmer (1986). Most of the models in the entrepreneurial finance literature assume a fixed distribution of types and investigate various aspects of entrepreneurship. We endogenize the types and show that a network formation can have striking effects on the equilibrium type configuration.

We consider a population of start-up entrepreneurs who are naturally endowed with inefficient projects but differ in their privately known cost of upgrading their projects (types) to efficient projects. The network is a group of entrepreneurs/projects who pass an imperfect screening mechanism performed by a large, established hub firm. Initially, each entrepreneur decides on whether to upgrade his project in the prospect of a possible network membership in the future. Given the configuration of types, entrepreneurs may apply to the hub firm for membership, which observes an imperfect signal about projects and accepts them on the basis of expected value. Entrepreneurs may reject the admission offer. Agglomeration of entrepreneurs in the network provides informational benefits to lenders and thus loans are available in a competitive market at two different rates, one for network members and one for outsiders. In this set-up, network membership has signaling value and opens the door to cheaper loans but comes at the cost of transferring an ownership share to the hub firm, which the hub firm self finances.

The more important feature of our model is that entrepreneurs' decisions to upgrade or not their projects before joining the network and the formation and size of the network are interrelated. We show that a network does not form if in equilibrium the fraction of efficient projects is too small or too large. Clearly, given the imperfect screening process, it would not be beneficial for the hub firm to form a network if there are too few efficient projects. If, on the other hand, the fraction of efficient projects is too large, none of these entrepreneurs will join the network even though the hub firm 
is willing to accept all, because lenders will infer that the network is all-inclusive and thus price loans as if there were no network. It follows that in equilibrium a network which effectively certifies projects cannot be all-inclusive; if it exists, the network must be selective, of an intermediate size.

Typically the benchmark case without a hub firm and a network has three equilibria. One of these is a corner equilibrium with no project upgrading. This is the unique equilibrium for very large costs of upgrading. Otherwise, it is Pareto dominated by one or two other equilibria, both of which display positive measures of entrepreneurs who upgrade their projects. Introducing the possibility of a network can have a negative or a positive effect. The negative effect can be a reduction in the measure of upgraded projects in one equilibrium, or emergence of a new equilibrium which is worse next to the bad no-upgrading-no-network equilibrium. Any positive effect, on the other hand, comes in the form of an increase in the measure of upgraded projects. Thus, the network may increase or decrease the equilibrium number of efficient projects and welfare.

Whenever the network increases welfare, it may do so with a technically stable or an unstable equilibrium, but the adverse effects appear only with a technically unstable equilibrium. We note that unstable equilibria should not be dismissed outright because project upgrade decisions are not reversible; nor do the entrepreneurs have an incentive to downgrade once upgraded. On the other hand, those who wish to upgrade ex post would need some time to react and build. So, when the entrepreneurs coordinate on a technically unstable network equilibrium that displays fewer upgraded projects relative to its counterpart without a network, we should expect the welfare decreasing effects to persist.

The network in our model is formed by a large, established hub firm with an 
imperfect screening ability. Two words of caution are required here. First, we focus solely on the screening function of networks. Second, whereas a network may of course be organized by various parties with different objectives, throughout the paper we stick to our "hub firm" interpretation of network organization. Our motivation comes from Lamoreaux et al. (2007), who provide a historical case study of entrepreneurial networks in Cleveland, Ohio, during the Second Industrial Revolution. They report how some established firms in the region (Brush Electric Company being an important one) acted as credible certifiers for networks of entrepreneurs in their search for finance:

[...] Inventors who were just starting their careers needed some [...] way to signal that their ideas were promising. Here Cleveland's industrial hubs played a critical role. Because they were collecting points for technological expertise, they served an important vetting function. Inventors seeking validation for their ideas gravitated to these hubs. So did business people in search of profitable investments (Lamoreaux et al., 2007).

Identification and the analysis of the environments in which information networks can grow and perform well are lively theoretical research topics. A reference paper is Crawford and Sobel (1982), which studies equilibrium information transmission between two parties (a single evaluator and a single user of evaluations) depending on congruence or divergence of interest. Saloner (1985) extends their analysis to the case of competing evaluators and studies the induced ranking of the candidates. Besides the possibility that it becomes a nepotism mechanism and performs flawed screening, the network can also produce an externality on excluded but qualified outsiders (whose worth the market underestimates). Taylor (2000), for example, 
shows that if the network is small, members are indifferent whereas outsiders are strictly better off from abolishing the network.

Inci (2008) focuses on the internal conflict of interest between qualified and not-soqualified network members and shows that the conflict is confined to small networks. In small networks, not-so-qualified members have a strong incentive to cripple the information mechanism while maintaining the network's unity but when the network becomes sufficiently large, they can "disguise in the crowd" and the conflict disappears. Parker (2008) analyzes the role of formal business networks in improving welfare by serving as mediums of sharing good and bad practices. He finds that the survival of a network greatly depends on its ability to exclude free-riders from continued membership.

From a technical point of view, our paper is closely related to Saloner (1985) where intermediaries are in a position to provide personal opinions on the likelihood of success of, say, personnel. Each intermediary decides whom to recommend from a group of individuals about whom he has private information. In our setting, acceptance to the network acts as a recommendation. In Saloner, the employer makes decisions based on his expectation about the quality of both the recommended and unrecommended applicants, which is similar to the functioning of the lender market in our model.

On the empirical side, our paper may be classified under the large literature that stresses the significance and importance of ties between firms and their creditors for the availability and cost of funds (among others see Petersen and Rajan, 1994, Uzzi, 1999, and Uzzi and Lancaster, 2003). Russo and Rossi (2001) find that firms in industrial districts may have lower cost of finance. Shane and Cable (2002) provide evidence on the importance of social ties in overcoming the information asymmetry 
between entrepreneurs and their potential financiers. The evidence in Biggs and Shah (2006) suggests that network firms have easier access to credit than stand-alone ones. Parker (2004) is a useful and extensive review of the entrepreneurship literature, empirical and theoretical.

The paper is organized as follows. Section 2 presents a simple model of costly project upgrading and loan market equilibrium under asymmetric information. Sections 3 and 4 discusses potential equilibria respectively in the absence and presence of a network organization. Section 5 concludes. An appendix contains the proofs and a brief discussion of alternative objectives for network organizers.

\section{The model}

We consider a unit mass of risk-neutral, penniless (nonatomic) heterogeneous entrepreneurs. Each entrepreneur is naturally endowed with a type- $L$, inefficient, start-up project which succeeds with probability $p_{L}$ and fails with probability $1-p_{L}$. However, an entrepreneur may choose to work hard to come up with a type- $H$, efficient, start-up project. This operation increases the probability of success to $p_{H}>p_{L}$ and $\operatorname{costs} c$ to the entrepreneur in terms of effort. The type of an entrepreneur is made up of a project-efficiency component $(L$ or $H$ ) and a cost component $c$ which we assume is distributed uniformly over the interval $[0, t]{ }^{4}$

All projects require the same start-up cost $I$ and yield the same return $Y$ in case of success, zero in case of failure. We shall denote by $\theta \in[0,1]$ the measure of type- $H$ entrepreneurs (efficient projects). ${ }^{5}$ Obviously, if an entrepreneur chooses to become a

\footnotetext{
${ }^{4}$ Our main results do not hinge on the assumption of uniform distribution of costs. Similar equilibria arise with other smooth distributions.

${ }^{5}$ We shall use the words "entrepreneur" and "project" interchangeably.
} 
type- $H$ entrepreneur, so does an entrepreneur with a lower cost of effort. Thus, given $\theta$ and the assumption of uniform distribution, we can define a critical cost level

$$
c(\theta)=t \theta
$$

such that entrepreneurs whose costs satisfy $c<c(\theta)$ become type- $H$ entrepreneurs and those with $c>c(\theta)$ remain type- $L$ entrepreneurs.

The true value of a project is its expected return net of investment costs. Therefore, denoting the risk-free interest rate in the economy by $r$, the true value of a project (to a type- $i$ entrepreneur) is

$$
\pi_{i}=p_{i} Y-(1+r) I \quad \forall i \in\{H, L\} \quad
$$

The effort cost $c$ does not show up in this expression since the value of a project is the value that is relevant to lenders when they are announcing their lending interest rate schedule and $c$ is already sunk and types are already determined at that moment. Entrepreneurs, of course, take into account their effort costs in deciding on whether to invest in an efficient project. We assume the following about the values of projects of different types.

\section{Assumption 1 (Values of projects) $p_{H} Y-t>(1+r) I>p_{L} Y$.}

This assumption states that the net value of the project of the type- $(H, t)$ entrepreneur (the one with the highest cost of effort) is positive but that of the type- $(L, 0)$ is negative. So, if they were to finance their projects from own resources, a type- $H$ entrepreneur would execute his project whereas a type- $L$ entrepreneur would not. 
A standard de Meza and Webb (1987) kind of competitive loan market funds the start-up projects. ${ }^{6}$ Lenders do not know the types of individual entrepreneurs; they only know the distribution of types. We assume limited liability in the sense that lenders cannot ask for something that an entrepreneur does not have. In this environment, funds have to be raised through standard debt contracts. The competitive loan price clears the market. Thus, given a fixed and constant cost of loanable funds (i.e., the risk-free interest rate $r$ ), all debt contracts must earn zero profits. Because lenders cannot distinguish between borrower types, they cannot provide separating contracts:

Lemma 1 There exists no separating equilibrium in the loan market.

The proof is in Appendix A.1. Given this result, only pooling contracts (either fully- or semi-pooling contracts) can be offered in the loan market. It is easy to find that the gross lending interest rate, $R(\lambda)$, is

$$
R(\lambda)=\frac{1+r}{p(\lambda)},
$$

where $\lambda$ is the fraction of type- $H$ borrowers in the loan applicant pool and $p(\lambda)$ is their average success probability:

$$
p(\lambda)=\lambda p_{H}+(1-\lambda) p_{L} .
$$

According to the equilibrium contract, type- $H$ entrepreneurs cross-subsidize type$L$ entrepreneurs. Type- $L$ entrepreneurs are able to get loans with desirable terms and

\footnotetext{
${ }^{6}$ One can alternatively assume that there are at least two risk-neutral lenders in Bertrand competition forming their beliefs about entrepreneurs' types and offering loan prices simultaneously and get the same results. See Inci $(2006,2008)$ for a formal derivation of the loan market equilibrium prices under Bertrand competition.
} 
this is the main reason why they might be tempted to engage in start-up activities. For example, if all entrepreneurs apply for loans, the fraction of type- $H$ entrepreneurs in the population at which the contracts are aimed is $\lambda=\theta$ and therefore the lending interest rate is $(1+r) / p(\theta)$. Note, for future reference, that $p^{\prime}(\lambda)>0$ and therefore $R^{\prime}(\lambda)<0$ for any $\lambda \in[0,1]$.

The final actor to be described in the model is an established firm which we call the hub firm. The hub firm is in the process of forming its network and receives informative but imperfect signals about entrepreneurs' types. Each signal can take on two values: good and bad. It is common knowledge that a type- $H$ entrepreneur gets a good signal with probability $x$ whereas a type- $L$ entrepreneur gets a good signal with probability $y<x$. We assume that network membership is observable, so lenders can identify whether an individual entrepreneur belongs to the network or not. This allows lenders to infer the fraction of different types of entrepreneurs both in and outside the network in a Bayesian sense.

The sequence of events is as follows. Entrepreneurs decide on whether to stay with the inefficient project or come up with an efficient project by incurring the effort cost. The hub firm receives signals about the type of each entrepreneur and then decides whether to include the entrepreneur to its network. Entrepreneurs may turn down the offer. Having determined their projects and having made their decision to join or not the network, entrepreneurs seek loans from lenders. Lenders observe network membership and decide which lending interest rate to offer to an entrepreneur. The loan market clears, financial contracts are signed and investments are made. Finally, project returns are realized and successful entrepreneurs payoff their loans. An entrepreneur cannot reverse his project upgrade decision once that stage of the game is over. 
In equilibrium, the competitive lending interest rate clears the loan market given subsequent decisions of the entrepreneurs and the hub firm. The hub firm's offer choice to each entrepreneur is optimal given its signal, and entrepreneurs' project decisions are individually optimal given all other actors' decisions and the marketclearing interest rate. Depending on the entrepreneur types who seek and obtain loans in the loan market, equilibria can be classified as fully- or semi-pooling.

\section{Equilibrium in the absence of a network}

We shall first characterize the loan market equilibrium for all levels of $\theta$ when there is no network organization. This analysis sets a useful benchmark. When $\theta$ is high, the equilibrium contract is a fully-pooling (all-inclusive) contract in which all type- $H$ and type- $L$ entrepreneurs participate. However, when $\theta$ is low, it is a semi-pooling contract with participation by all type- $H$ entrepreneurs along with a fraction of type$L$ entrepreneurs.

Consider a fully-pooling loan contract first. Obviously, such a contract must involve an interest rate acceptable to both entrepreneur types. For a type- $L$ entrepreneur to prefer the pooling contract, the cross-subsidy via this contract must be large enough to produce a positive expected value for his project. In this case, the payoff of a type- $L$ entrepreneur is $Y-R(\theta) I$ if the project is successful and otherwise zero by limited liability. The lending interest rate of this contract is $(1+r) / p(\theta)$.

When cross-subsidies are small, such that the expected value of type- $L$ entrepreneurs' projects is negative, the equilibrium contract cannot be fully pooling. Nor does a separating equilibrium exist as stated in Lemma 1 . The only remaining possibility is a semi-pooling equilibrium. In this loan market equilibrium, in addition to all type- $H$ 
entrepreneurs, a measure of type- $L$ entrepreneurs participate until the interest rate is driven up sufficiently high so that type- $L$ entrepreneurs make zero expected profits whether they take a loan or not.

The lending interest rate in a semi-pooling equilibrium is $(1+r) / p(\theta /[\theta+(1-$ $\theta) \mu]$ ) where $\mu$ denotes the measure of type- $L$ agents who take loans and become entrepreneurs. Note that when type- $L$ entrepreneurs make zero expected profits, type$H$ entrepreneurs also make zero expected profits (once again this argument excludes the nonpecuniary cost of effort). Consequently, the expected value of a project for a type- $i$ entrepreneur is

$$
V_{i}(\theta)=\max \left[0, p_{i}(Y-R(\theta) I)\right] \quad \forall i \in\{H, L\} \quad .
$$

The term $Y-R(\theta) I$ is monotonic increasing and concave in $\theta$. Let $\bar{\theta}$ be the fraction of type- $H$ entrepreneurs such that $Y-R(\bar{\theta}) I=0$. A fully-pooling contract is offered when $\theta>\bar{\theta}$ and a semi-pooling one is offered when $\theta \leq \bar{\theta}$.

Turning now to the effort decisions of the entrepreneurs, ex ante, an entrepreneur prefers working hard to come up with a type- $H$ project as long as $V_{H}(\theta)-V_{L}(\theta) \geq c(\theta)$. That is, given a fraction $\theta$ of type- $H$ entrepreneurs in the economy, the expected extra benefit from upgrading one's project should be at least as large as its cost. The analytically interesting equilibria are those in which a positive measure of agents chooses to become type- $H$ entrepreneurs. In such equilibria, the fraction of type$H$ entrepreneurs satisfies $1>\theta>\bar{\theta}$, where the cost of the marginal entrepreneur (the agent who is indifferent between becoming a type- $H$ and remaining a type- $L$ entrepreneur) must satisfy

$$
c\left(\theta^{*}\right)=\left(p_{H}-p_{L}\right)\left[Y-R\left(\theta^{*}\right) I\right]
$$


Here, $\theta^{*}$ denotes the equilibrium fraction of type- $H$ entrepreneurs (equivalently, the fraction of efficient projects) in the economy. We call the LHS of this equation the cost side and the RHS the benefit side. We know from (1) that $c(\theta)=t \theta$ under the assumption of uniform distribution. The benefit side, on the other hand, is a monotonic increasing function of $\theta$ when fully-pooling contracts are offered because $R^{\prime}(\theta)<0$. It is also easy to verify that this function is concave. Using the fact that the lending interest rate in a fully-pooling equilibrium is $R(\theta)=(1+r) /\left[\theta p_{H}+(1-\theta) p_{L}\right]$, we find that the marginal entrepreneur, given any $1>\theta^{*}>\bar{\theta}$, must satisfy

$$
t \theta^{*}=\left(p_{H}-p_{L}\right)\left[Y-\frac{(1+r) I}{\theta^{*} p_{H}+\left(1-\theta^{*}\right) p_{L}}\right] .
$$

Proposition 1 (Interior equilibria) In the absence of a network organization, in interior equilibria the location of the marginal entrepreneur (equivalently, the measure of upgraded projects) $\theta^{*}$ is defined by (7).

The expression in (7) is quadratic in $\theta$, which formally proves that there can be at most two interior equilibria. Given the production technology and the risk-free interest rate, the existence and number of the equilibrium types are parametrically determined by $t$.

The only equilibrium in the range $\theta \leq \bar{\theta}$ is a corner solution. For $\theta$ in this range, there are no returns from becoming a type- $H$ entrepreneur because both types earn zero expected profits. Consequently, the equilibrium occurs at $\theta^{*}=0$. It is immediate to see that this equilibrium always exists regardless of the value of $t$. There may be another corner solution at $\theta^{*}=1$ whenever the benefit of becoming a type- $H$ entrepreneur is at least as high as its cost at this point.

Figure 1 depicts the equilibria for a parameter configuration. It shows the fraction 


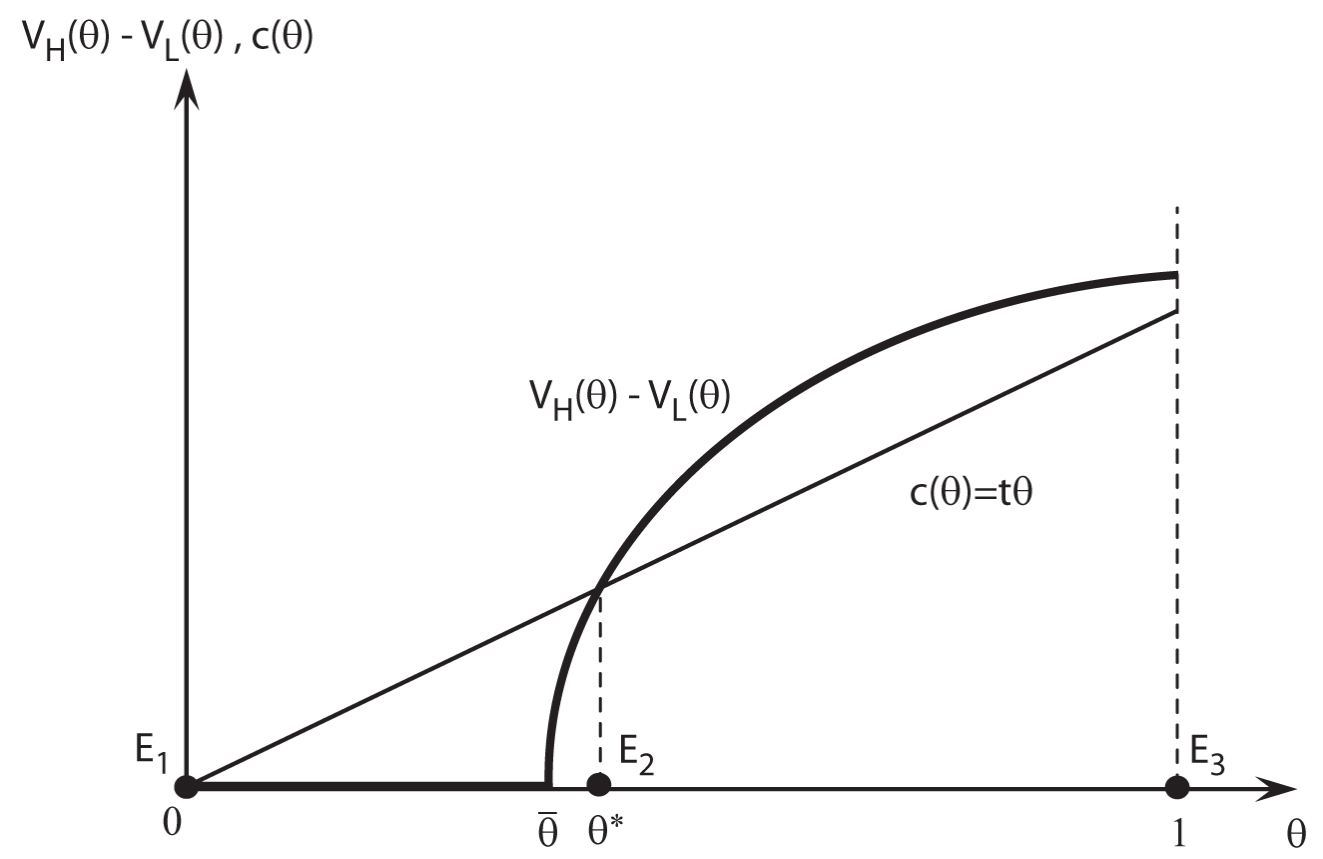

Figure 1: An equilibrium configuration when there is no network

of type- $H$ entrepreneurs on the $x$-axis and the cost and benefit of the marginal entrepreneur on the $y$-axis. When $\theta<\bar{\theta}$, the benefit from investing in quality does not vary with $\theta$ and stays vertical at zero. When $\theta \geq \bar{\theta}$, the marginal entrepreneur's benefit monotonically increases until $\theta=1$ where we obtain a first-best efficient contract as there are no type- $L$ entrepreneurs at this right end. Intersections of the benefit with the cost identify an interior equilibria where the marginal entrepreneur is indifferent between becoming type- $H$ and remaining type- $L$. Such an interior equilibrium is located at $E_{2}$ in Figure 1. There are also two corner solutions in this configuration: $E_{1}$ with no type- $H$ entrepreneurs and $E_{3}$ with no type- $L$ entrepreneurs.

Depending on the cost parameter $t$, there can be other equilibrium configurations. When, for example, $t=t_{1}$ as shown in Figure 2, the cost line cuts the benefit curve twice. In this case, $E_{1}$ remains unchanged but we have two new interior equilibria $\left(E_{2}^{\prime}\right.$ and $\left.E_{3}^{\prime}\right)$, one of which $\left(E_{3}^{\prime}\right)$ replaces the right-end corner equilibrium of Figure 1 


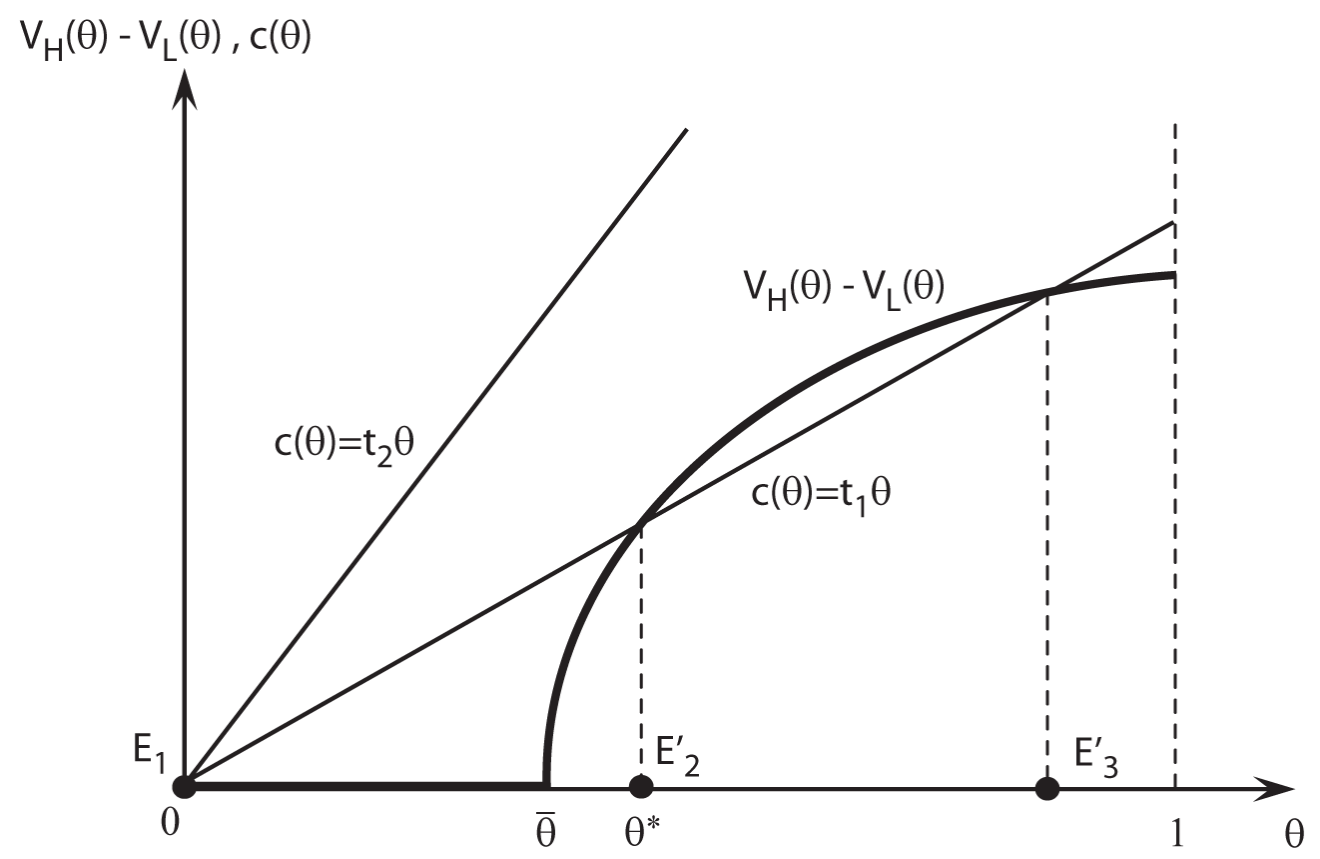

Figure 2: Other equilibrium configurations when there is no network

$\left(E_{3}\right)$. When $t$ is very high (as in the case in which $t=t_{2}$ as shown in Figure 2), a unique equilibrium occurs at $\theta=0$.

Some comments on the properties of equilibria are in order. Because the cost line always cuts the benefit curve at $\theta=0$, existence of equilibrium is not an issue. Whenever multiple equilibria occur, they can be Pareto-ranked: trivially, an equilibrium Pareto dominates another equilibrium if its $\theta^{*}$ is larger. In general, the middle- $\theta$ equilibrium (i.e., $E_{2}$ in Figure 1 and $E_{2}^{\prime}$ in Figure 2) is technically unstable. In the next section, we show that a network can emerge in both a technically stable and an unstable equilibrium, and that the network is not socially desirable whenever it is formed by a technically unstable equilibrium. It is therefore useful to elaborate on the behavior of our economy around equilibria like $E_{2}$ based on "heuristic dynamics" that follow perturbations to the fraction of upgraded projects, $\theta$.

Formation and persistence of equilibria depend on the underlying disequilibrium 


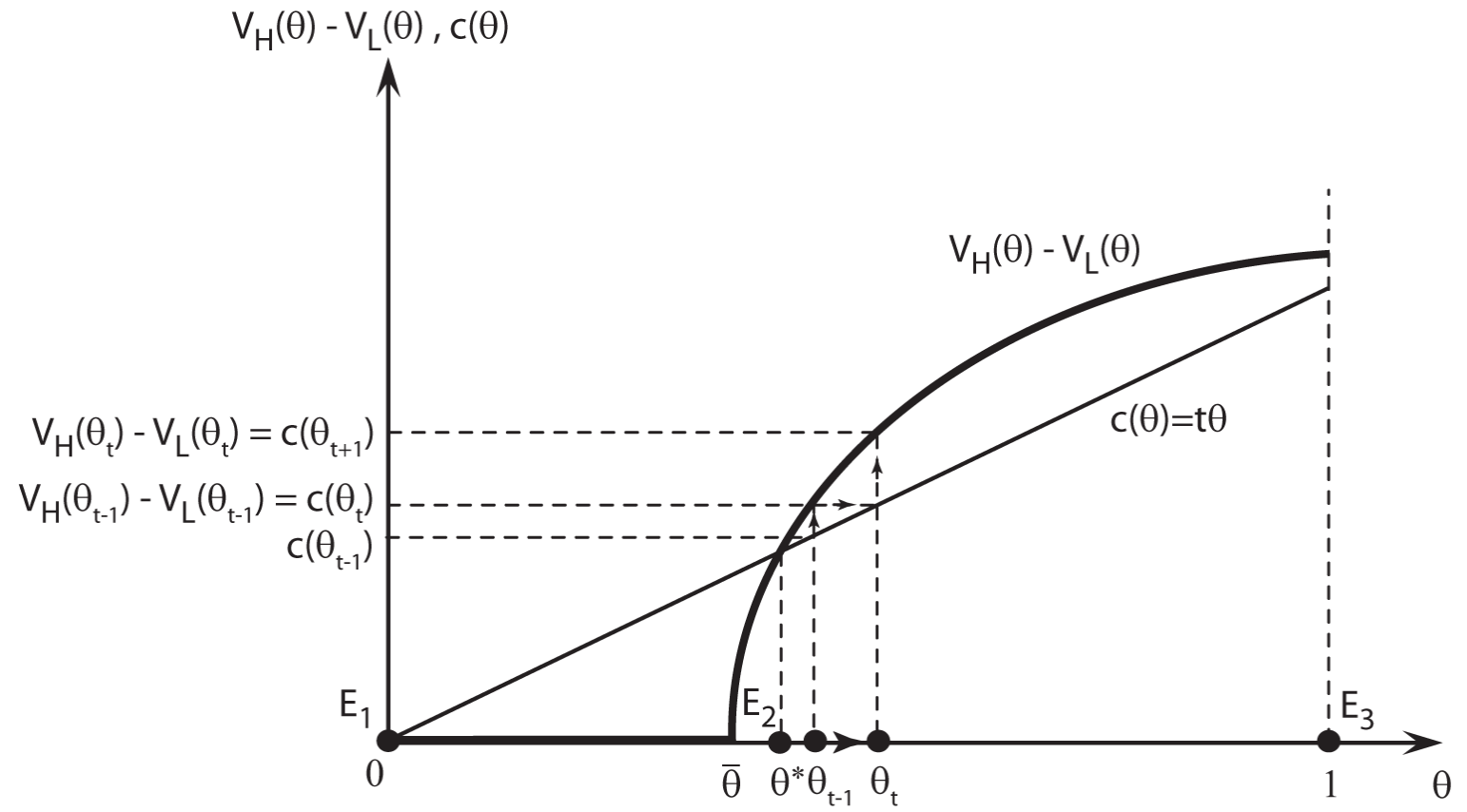

Figure 3: Disequilibrium adjustment

adjustment processes. A reasonable adjustment mechanism that acknowledges the irreversibility of project upgrade decisions is

$$
\theta_{t}= \begin{cases}\theta_{t-1}+\Omega\left(V_{H}\left(\theta_{t-1}\right)-V_{L}\left(\theta_{t-1}\right)-c\left(\theta_{t-1}\right)\right) & \text { if } \theta_{t-1}>\theta^{*} \\ \theta_{t-1} & \text { if } \theta_{t-1} \leq \theta^{*}\end{cases}
$$

where $\theta_{t}$ is the fraction of type- $H$ entrepreneurs at time $t$ and $\Omega(\cdot)$ is a monotonic increasing function. According to this formulation, the fraction of type- $H$ entrepreneurs at time $t$ equals to the fraction of type- $H$ entrepreneurs at time $t-1$ plus a monotonic function of the net benefit of becoming a type- $H$ entrepreneur at time $t-1$. When, for example, the economy is at a disequilibrium point with $\theta_{t-1}>\theta^{*}$ as shown in Figure 3, agents with upgrading costs between $c\left(\theta_{t-1}\right)$ and $c\left(\theta_{t}\right)$ will find it beneficial to upgrade their projects. Thus, we expect to see that the fraction of upgraded projects increases by $\theta_{t}-\theta_{t-1}$. Of course, all of those who see the immediate 
benefit may not be able to act immediately, which is why we have the function $\Omega(\cdot)$ as a control for the speed of adjustment.

The adjustment process in (8) can be a consequence of the young generation of entrepreneurs inheriting the projects and skills from the old. In line with the sequence of events of the model, each generation of entrepreneurs would make their upgrade decisions once and before their network membership and financing decisions. ${ }^{7}$ While the adjustment process under this interpretation could be rather slow, a plausible and relatively fast process is depicted in Figure 3, based on gradual reactions to positive individual net benefits from project upgrading. In any case, one should not expect an instantaneous adjustment to eliminate the technically unstable, socially undesirable equilibria because agents need time to interpret the market outcome, develop an upgrade, and build their project.

Plausible potential causes for emergence of a disequilibrium $\theta$ include coordination failures (i.e., the possibility that a small fraction of the population focuses on the "wrong" equilibria located at $E_{1}$ and $E_{3}$ while the large majority expects $E_{2}$ will be played). It could also be a shock or a stochastic element in the project upgrading technology. Suppose, contrary to our working assumption, that the project upgrading effort actually succeeds with probability less than one. One can imagine that each entrepreneur's upgrading cost $c$ is uncertain, in the form $c+\epsilon$, where $c$ is private knowledge and $\epsilon \in[-\delta, \delta]$ is a random variable with mean zero, unknown at the time of the upgrading decision, and $\delta$ is very small. Now, the realized measure of upgraded projects, denoted by $\theta_{F}$, will diverge from $\theta^{*}$ of $E_{2}$ in Figure 3.

If $\theta_{F}<\theta^{*}$ is realized, there will exist type- $H$ entrepreneurs who ex post find out

\footnotetext{
${ }^{7}$ We may possibly have an overlapping generations setting in which the young generation is in the upgrading stage when the old generation is in business. In this setting, the young generation would be a replica of the old with the additional opportunity of upgrading the project.
} 
that they would have done better by not upgrading their projects because the benefit of upgrading a project turns out be less than its cost (i.e., $V_{H}\left(\theta_{F}\right)-V_{L}\left(\theta_{F}\right)<c\left(\theta_{F}\right)$ for $\left.\theta_{F}<\theta^{*}\right)$. However, the upgrading cost is already incurred and it is still the case that $V_{H}\left(\theta_{F}\right) \geq 0$, so these type- $H$ entrepreneurs will remain active. More importantly, nor will there be new project upgrades in the future because the corresponding benefit is negative for all entrepreneurs who chose to remain type- $L$. In this case, we have a stable measure of upgraded projects, forming a fraction $\theta_{F}<\theta^{*}$ of all entrepreneurs. If $\theta_{F}>\theta^{*}$ is realized, the marginal entrepreneur will observe a positive benefit from project upgrading. This invites new upgrades but, as discussed above, upgrades take time to come into being and so the undesirable effects of the network may persist. Eventually, the entrepreneurs located at the right of $\theta_{F}$ will start upgrading and $\theta$ will move toward its new stable equilibrium level at $E_{3}$.

\begin{tabular}{ccccccc}
\hline \hline & $I$ & $p_{H}$ & $p_{L}$ & $r$ & $Y$ & $t$ \\
\hline$E_{2}^{\prime}$-type equilibria: & + & - & $?$ & + & - & + \\
$E_{3}^{\prime}$-type equilibria: & - & + & $?$ & - & + & - \\
\hline \hline
\end{tabular}

Table 1: Comparative statics on interior equilibria

We close our analysis of equilibria in the absence of a network by summarizing the comparative static properties of interior equilibria in Table 1. An increase in investment size, risk-free interest rate, or the highest possible cost of effort increase the equilibrium fraction of type- $H$ entrepreneurs for all $E_{2}^{\prime}$-type equilibria whereas they decrease that for all $E_{3}^{\prime}$-type equilibria. However, an increase in the success probability of a type- $H$ entrepreneur or what an entrepreneur obtains in a success state decrease the equilibrium fraction of type- $H$ entrepreneurs for all $E_{2}^{\prime}$-type equilibria whereas they increase that for all $E_{3}^{\prime}$-type equilibria.

The comparative static properties of equilibria with respect to $p_{L}$ are in general ambiguous. This can be observed from (7). An increase in $p_{L}$ does not change the 
cost side, but it decreases $\left(p_{H}-p_{L}\right)$ part of the benefit side at the same time that it increases the expression in the square brackets. Thus, whether the equilibrium fraction of type- $H$ entrepreneurs increases or decreases depends on the remaining parameters that are linked to the macroeconomic conditions, in particular the riskfree interest rate, and the current technology.

\section{Equilibrium when there is a network}

Having derived and analyzed the equilibria of the benchmark model, we are now in a position to introduce the network into the scheme. We shall analyze the decisions of the hub firm and entrepreneurs in turn before characterizing the equilibrium when there is a network.

As we mentioned in the Introduction, our motivation for the hub firm comes from Lamoreaux et al. (2007). In this historical case study, Brush Electric Company is found to be one of the important hubs for entrepreneurs who are in the process of starting their firms. Three important points of this case study are relevant to our modeling strategy. First, hub firms were clearly helping network entrepreneurs in finding (possibly cheaper) finance from lenders. They had good relations with banks and even organized financial institutions by themselves, which then financed some of the network entrepreneurs. This justifies why being part of a hub firm's network serves as a signal. Second, Lamoreaux et al. (2007) provide evidence about significant shares held by hub firms in the firms started by network entrepreneurs. Holding such shares is not only a profitable business for a hub firm since it invests in promising start-up projects, but it also ensures the credibility of the signals in the minds of financiers. This justifies why equity is used in the model and shows the background 
role of equity. ${ }^{8}$ Third, these hub firms were usually established firms with a history of successful commercialization of many innovative ideas, suggesting that they are in a better position than the market in determining the "types" of entrepreneurs. This justifies both why hub firms have deep pockets and have informative signals.

\subsection{The hub firm's problem}

The hub firm faces a simple binary choice problem: accept an entrepreneur as member or reject. If the hub firm accepts the entrepreneur, it asks for a fixed share $\alpha \in(0,1)$ of the start-up and self finances this portion. It gets the positive payoff $\alpha \pi_{H}$ if the entrepreneur turns out to be a type- $H$ and the negative payoff $\alpha \pi_{L}$ if the entrepreneur turns out to be a type- $L$. If the hub firm rejects the entrepreneur, it gets zero payoff.

The hub firm can only observe $\theta$ but not the type of an individual entrepreneur. It just gets an imperfect but informative signal of the type. According to the signal structure explained before, the probability that a type- $H$ entrepreneur gets a good signal is $x$ and the probability that a type- $L$ entrepreneur gets a good signal is $y$, where $x>y$. The hub firm calculates its expected payoffs from accepting and rejecting an entrepreneur by formulating the Bayesian inferences from the signals it receives. ${ }^{9}$

After an observation of a good signal, the posterior probability that the entrepreneur is type- $H$ is

$$
G(\theta)=\frac{x \theta}{x \theta+y(1-\theta)},
$$

and after an observation of a bad signal, the posterior probability that the entrepre-

\footnotetext{
${ }^{8}$ It is worth noting that if observing the signals is costly to a hub firm, it might well prefer to not to extract them. It can rather accept members randomly or based on other things, which would then break the credibility of its signaling. In fact, Inci (2008) shows that the signals of a hub firm are reliable if it holds a sufficiently large stake in the network firms.

${ }^{9}$ Appendix A.3 discusses some alternative objectives of a network organizer.
} 
neur is type- $H$ is

$$
B(\theta)=\frac{(1-x) \theta}{(1-x) \theta+(1-y)(1-\theta)} .
$$

It is easy to show that $G(\theta)>B(\theta)$ for every $\theta$ due to the fact that $x>y$.

Using (9) and (10) the expected payoff from acceptance can be written as a function of the signal:

$$
\Pi^{J}(\theta)=J(\theta) \alpha \pi_{H}+[1-J(\theta)] \alpha \pi_{L} \quad \forall J \in\{G, B\} \quad,
$$

where $J=G$ if the signal is good and $J=B$ if the signal is bad. The hub firm is indifferent between accepting an entrepreneur with a good signal to the network and rejecting him when $\Pi^{G}\left(\theta_{x}\right)=0$, where $\theta_{x}$ is the critical value of the fraction of type- $H$ entrepreneurs. Manipulating this yields

$$
\theta_{x}=\frac{-y \pi_{L}}{x \pi_{H}-y \pi_{L}}
$$

Similarly, we can define a critical $\theta_{y}$ for the case of a bad signal through $\Pi^{B}\left(\theta_{y}\right)=0$ :

$$
\theta_{y}=\frac{-(1-y) \pi_{L}}{(1-x) \pi_{H}-(1-y) \pi_{L}}
$$

The comparative static properties of the thresholds $\theta_{x}$ and $\theta_{y}$ are given in Table 2. An increase in investment size or risk-free interest rate increase both thresholds while an increase in success probabilities or what an entrepreneurs obtains in the success state decrease both of them. However, an increase in the probabilities that an entrepreneur gets a good signal has opposite effects on the thresholds: an increase in $x$ decreases $\theta_{x}$ but increases $\theta_{y}$ while an increase in $y$ increases $\theta_{x}$ but decreases $\theta_{y}$. 


\begin{tabular}{cccccccc}
\hline \hline & $I$ & $p_{H}$ & $p_{L}$ & $r$ & $Y$ & $x$ & $y$ \\
\hline$\theta_{x}$ & + & - & - & + & - & - & + \\
$\theta_{y}$ & + & - & - & + & - & + & - \\
\hline \hline
\end{tabular}

Table 2: Comparative statics on $\theta_{x}$ and $\theta_{y}$

Since $x>y$, it is easy to show that $\theta_{y}>\theta_{x}$ and this leads to the following proposition.

Proposition 2 (Hub firm's decision) i) If $\theta<\theta_{x}$, the hub firm rejects all entrepreneurs from the network regardless of the signals; ii) If $\theta_{y} \geq \theta \geq \theta_{x}$, it accepts only the entrepreneurs with good signals to the network; iii) If $\theta>\theta_{y}$, it accepts all entrepreneurs to the network regardless of the signals.

This proposition is quite intuitive. Accepting a type- $H$ entrepreneur is always profitable whereas accepting a type- $L$ entrepreneur produces a loss. When $\theta<\theta_{x}$ so that the proportion of type- $H$ entrepreneurs is very small, an accepted entrepreneur is highly likely a type- $L$ entrepreneur no matter the signal. Then, it is better not to offer any membership. When $\theta>\theta_{y}$, the opposite happens: there are many type- $H$ and only a few type- $L$ entrepreneurs, so the hub firm is willing to accept all entrepreneurs regardless of the signals. Finally, when $\theta_{y} \geq \theta \geq \theta_{x}$, accepting an entrepreneur is profitable if he has a good signal because there are sufficiently many type- $H$ entrepreneurs among those who got good signals. However, the group with bad signals includes too many type- $L$ entrepreneurs, which makes it optimal for the hub firm to reject them all. 


\subsection{Entrepreneurs' problem}

We now focus on the project upgrading decisions by the entrepreneurs. Formation of a network generates two groups of entrepreneurs in the economy: network entrepreneurs (denoted by $N$ ) and outsiders, or stand-alone entrepreneurs (denoted by $S$ ). Denote by $R^{N}(\theta)$ the lending interest rate to network entrepreneurs and by $R^{S}(\theta)$ the lending interest rate to stand-alone entrepreneurs. The payoff of a type- $i$ network entrepreneur is ${ }^{10}$

$$
N_{i}(\theta)=p_{i}(1-\alpha)\left[Y-R^{N}(\theta) I\right] \quad \forall i \in\{H, L\} \quad .
$$

Since the signals are informative, if a network is formed in equilibrium, lenders provide loans to network entrepreneurs with better terms. Consequently, a network entrepreneur trades off a share of his project to the hub firm for a cheaper loan as network member. A stand-alone entrepreneur, on the other hand, owns the whole project but, because the stand-alone population comprises a worse sample of entrepreneurs in terms of average success probability than the network, is offered a loan with higher interest rate. As a result, the payoff of a type- $i$ stand-alone entrepreneur is

$$
S_{i}(\theta)=p_{i}\left[Y-R^{S}(\theta) I\right] \quad \forall i \in\{H, L\} \quad .
$$

Particular values of $R^{N}(\theta)$ and $R^{S}(\theta)$ in (14) and (15) depend on the fraction of type- $H$ entrepreneurs in network and stand-alone populations, which in turn depend on the type of regime which the economy is currently in according to Proposition 2.

One requirement for existence of a network in equilibrium is that the share $\alpha$ of

\footnotetext{
${ }^{10}$ This expression, and the one below in $(15)$, exclude the cost $c(\theta)$ of upgrading a project. It is convenient to incorporate this cost when analyzing the entrepreneurs' project upgrading decisions.
} 
the start-up that the hub firm asks for is not too large. Thus, network entrepreneurs must prefer to stay in the network (i.e., both $N_{H}(\theta)>S_{H}(\theta)$ and $N_{L}(\theta)>S_{L}(\theta)$ must hold when $\theta_{x}<\theta<\theta_{y}$ ). The following assumption, obtained from (14) and (15), states a primitive condition for these inequalities to hold.

Assumption $2($ Share $\alpha) \alpha<\max _{\theta \in\left[\theta_{x}, \theta_{y}\right]}\left\{\left[\left(R^{S}(\theta)-R^{N}(\theta)\right) I\right] /\left[Y-R^{N}(\theta) I\right]\right\}$.

Our results hold for all $\alpha$ satisfying this assumption, that is, as long as the "entrance share" $\alpha$ is higher than the threshold defined in this assumption. On the other hand, a network does not form if $\alpha$ is lower than the threshold. This is a working assumption. We could, for example, introduce a generalized Nash Bargaining game as a surplus sharing rule to endogenize $\alpha$, à la Harsanyi and Selten (1972). Our specification is a shortcut to the solution of this kind of bargaining in which none of the parties has all the bargaining power (See Kono (2006) for an application of generalized Nash Bargaining in network formation setting).

Proposition 2 leaves three options for the hub firm: accept all entrepreneurs unconditionally, accept only the entrepreneurs with good signals, or reject all entrepreneurs unconditionally. Below we analyze the decision of an entrepreneur regarding network membership in each of these three regimes. The following lemma is useful for this purpose. The proof is given in Appendix A.2.

Lemma 2 (Thresholds) $\theta_{x}<\bar{\theta}<\theta_{y}$.

Consider first the case $\theta<\theta_{x}$. The hub firm's optimal decision is to reject an entrepreneur no matter whether the signal is $x$ or $y$. When the entrepreneur has no chance but to become a stand-alone entrepreneur, the aggregate level implication is 
dispersion of firms in the region and thus the lending interest rate is as given by the benchmark model. However, we also know from the benchmark model that both types of entrepreneurs make zero expected payoffs in the interval $[0, \bar{\theta}]$, which includes the interval $\left[0, \theta_{x}\right]$ as stated in Lemma 2. Consequently, the lending interest rate in the interval $\left[0, \theta_{x}\right]$ is $R^{S}(\theta)=(1+r) / p(\theta /[\theta+(1-\theta) \mu])$.

Second, when the fraction of type- $H$ entrepreneurs is in the intermediate range (i.e., $\theta \in\left[\theta_{x}, \theta_{y}\right]$ ), an entrepreneur is accepted to the network only if he gets a good signal, which happens with probability $x$. By Assumption 2, such an entrepreneur prefers joining the network and gets the payoff $N_{H}(\theta)$. Otherwise, with probability $1-x$, he is rejected from the network, becomes a stand-alone entrepreneur and gets the payoff $S_{H}(\theta)$. Therefore, from an ex ante point of view, the expected benefit from becoming a type- $H$ entrepreneur is $x N_{H}(\theta)+(1-x) S_{H}(\theta)$ in the interval $\left[\theta_{x}, \theta_{y}\right]$. These decisions at the micro level have aggregate implications on the industry architecture. ${ }^{11}$ All entrepreneurs who get a good signal join the network, so the probability that a network entrepreneur is of type- $H$ is $G(\theta)$ and the lending interest rate offered to a network entrepreneur is $R^{N}(\theta)=(1+r) / p(G(\theta))$. All entrepreneurs who get a bad signal stand alone and are offered the lending interest rate $R^{S}(\theta)=(1+r) / p(B(\theta))$.

The last case is $\theta>\theta_{y}$. When the fraction of type- $H$ entrepreneurs is larger than $\theta_{y}$, the hub firm is willing to accept an entrepreneur to the network no matter whether the signal is $x$ or $y$. Yet, an entrepreneur no longer finds it beneficial to join the network. Joining the network means giving up an $\alpha$ share of the firm in return for better loan terms as a network member. However, this benefit disappears when everyone joins the network because lenders infer that everyone is in the network

\footnotetext{
${ }^{11}$ There are $x \theta$ type- $H$ and $y(1-\theta)$ type- $L$ entrepreneurs in the network. At the same time, there are $(1-x) \theta$ type- $H$ and $(1-y)(1-\theta)$ type- $L$ entrepreneurs who stand alone. This is nothing but a partial agglomeration of firms in the region.
} 
and thus set the lending interest rate accordingly, which would be nothing but the lending interest rate in the absence of a network. Hence, even though the hub firm is willing to let all entrepreneurs in, none of them will do so. As a result, we observe a complete dispersion of firms. The lending interest rate is then the same as the lending interest rate in the benchmark model, $R^{S}(\theta)=(1+r) / p(\theta)$. The following proposition summarizes the discussion.

Proposition 3 (Entrepreneurs' decision) When $\theta<\theta_{x}$ or $\theta>\theta_{y}$, all entrepreneurs stand alone. When $\theta_{y} \geq \theta \geq \theta_{x}$, entrepreneurs with good signals join the network and the rest stand alone.

This may raise the question as to whether the hub firm has any preference for decreasing $\alpha$ so that type- $H$ entrepreneurs start becoming members when $\theta>\theta_{y}$. The answer is "no" simply because, for all possible $\alpha$ values, whenever type- $H$ entrepreneurs prefer to join the network, their type- $L$ counterparts also prefer joining. Thus, decreasing the hub firm's share for $\theta>\theta_{y}$ does not change entrepreneurs' decisions. Moreover, no entrepreneur has an incentive to deviate and join the network. If one does, from the perspective of the lenders this action has no signaling value about the entrepreneur's type. Thus, he will be offered the same interest rate regardless of his network membership status.

An immediate corollary of Proposition 3 is the following.

Corollary 1 A network is formed only when $\theta_{x} \leq \theta \leq \theta_{y}$. 


\subsection{The decision to upgrade a project}

Having derived the hub firm's and entrepreneurs' decisions, we now turn to the analysis of an entrepreneur's decision to upgrade his project. We can write the expected benefit from becoming a type- $H$ entrepreneur, $\mathcal{V}_{H}(\theta)$, as follows:

$$
\mathcal{V}_{H}(\theta)=\left\{\begin{array}{ll}
0 & \text { if } \theta<\theta_{x} \\
x N_{H}(\theta)+(1-x) S_{H}(\theta) & \text { if } \theta_{x} \leq \theta \leq \theta_{y} \\
S_{H}(\theta) & \text { if } \theta>\theta_{y}
\end{array} .\right.
$$

In the same fashion, we can write the expected benefit from remaining a type- $L$ entrepreneur, $\mathcal{V}_{L}(\theta)$, as follows:

$$
\mathcal{V}_{L}(\theta)=\left\{\begin{array}{ll}
0 & \text { if } \theta<\theta_{x} \\
y N_{L}(\theta)+(1-y) S_{L}(\theta) & \text { if } \theta_{x} \leq \theta \leq \theta_{y} \\
S_{L}(\theta) & \text { if } \theta>\theta_{y}
\end{array} .\right.
$$

From an ex ante point of view, when $\theta_{x} \leq \theta \leq \theta_{y}$, an entrepreneur prefers joining the network if $\mathcal{V}_{H}(\theta)>S_{H}(\theta)$ and $\mathcal{V}_{L}(\theta)>S_{L}(\theta)$, which are guaranteed by Assumption 2.

An entrepreneur prefers to upgrade his project if and only if doing so brings an extra expected payoff:

$$
\mathcal{V}_{H}(\theta)-c(\theta)>\mathcal{V}_{L}(\theta)
$$

Graphical analysis of (18) can be made by modifying the figures we constructed in the benchmark model. The only modification is in the benefit curve for $\theta \in\left[\theta_{x}, \theta_{y}\right]$, where a network is formed. The introduction of the network increases the payoff of the marginal entrepreneur for all $\theta \in\left[\theta_{x}, \theta_{y}\right]$ (i.e., the black curves in Figures 4, 5, 
and 6 replace the gray curves under them). The parts of the benefit curve in the ranges $\left[1, \theta_{x}\right)$ and $\left[\theta_{y}, 1\right)$ remain unchanged. As a result, the benefit curve, which is now denoted by $\mathcal{V}_{H}(\theta)-\mathcal{V}_{L}(\theta)$, consists of three piecewise-continuous parts rather than two.

We shall work out three equilibrium configurations that are of interest. The first one, shown in Figure 4, depicts the traditional view on networks: the introduction of a network increases the equilibrium fraction of type- $H$ entrepreneurs. The second one, shown in Figure 5, is more interesting in that the equilibrium fraction of type- $H$ entrepreneurs is reduced following formation of a network. Yet, a third one is shown in Figure 6 to facilitate the idea that a network that increases the fraction of type- $H$ entrepreneurs is not necessarily stable.

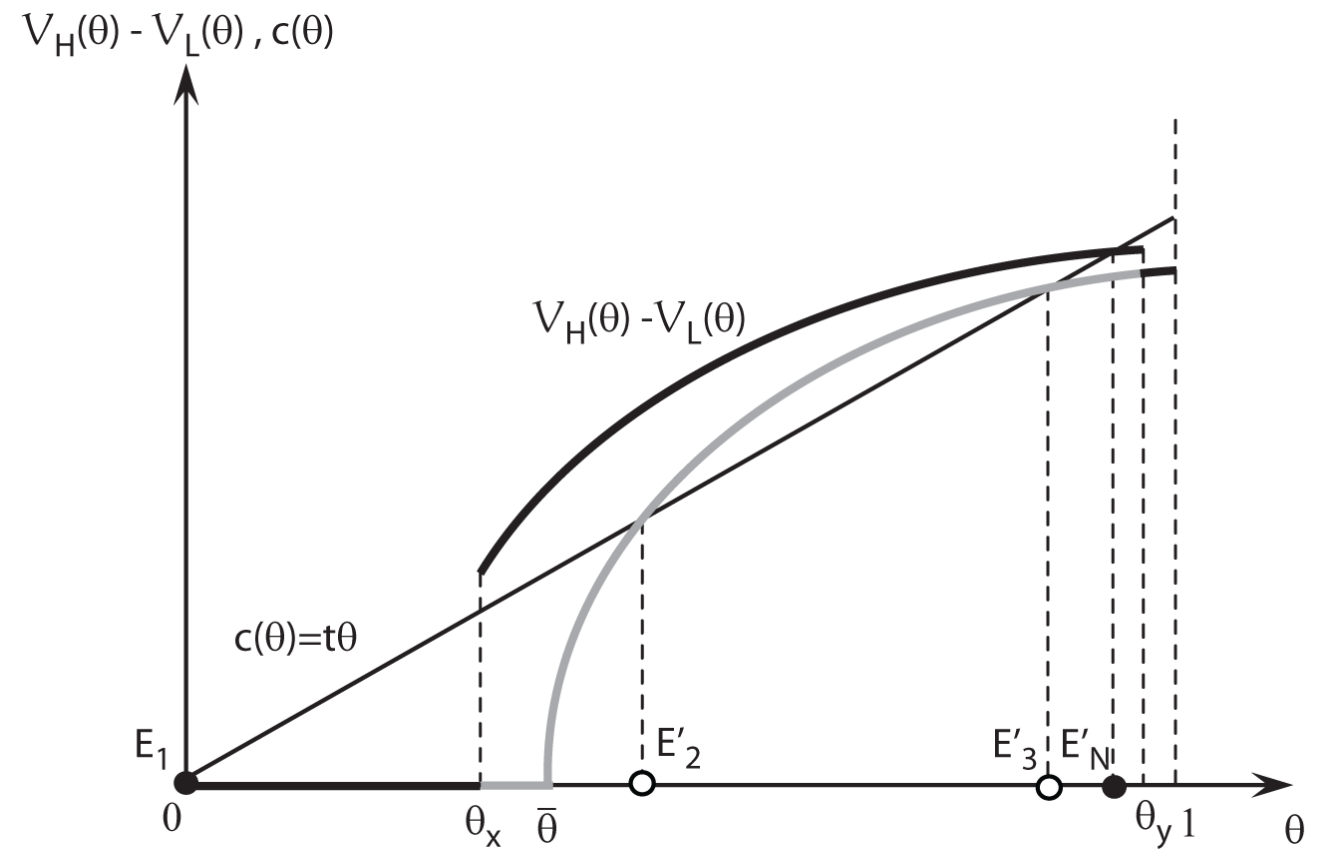

Figure 4: An equilibrium configuration when there is a network: case 1

The first equilibrium configuration, shown in Figure 4, replaces Figure 2 when there is a network. As a result of the network, the gray curve is replaced by the black 
curve above it. Consequently, $E_{1}$ remains unchanged, $E_{2}^{\prime}$ disappears, while $E_{3}^{\prime}$ is replaced by $E_{N}^{\prime}$. Notice that if a network is formed, which happens only in $\left[\theta_{x}, \theta_{y}\right]$, it is formed only at $E_{N}^{\prime}$, which is associated with a larger equilibrium fraction of type- $H$ entrepreneurs than $E_{3}^{\prime}$.

The intuition is the following. When we introduce the network, the (expected) benefit of both type- $H$ and type- $L$ entrepreneurs increases while their costs stay the same. As a result, $E_{3}^{\prime}$ can no longer be an equilibrium. Then, the question is who would be the new marginal entrepreneur who is indifferent between upgrading his project or not. At $E_{3}^{\prime}$, the marginal net benefit from upgrading the project is lower than the marginal net benefit from not upgrading it (i.e., $d\left[\mathcal{V}_{H}(\theta)-c(\theta)\right] / d \theta<$ $\left.d \mathcal{V}_{L}(\theta) / d \theta\right)$. Therefore, the new marginal entrepreneur has to be to the right of the original one and hence the new equilibrium occurs at a higher $\theta$. Consequently, the network improves total welfare. This equilibrium is technically stable with respect to perturbations on $\theta$.

The positive story of networks in the previous paragraphs is not universal. Figure 5, which replaces Figure 1 when there is a network, depicts another equilibrium configuration. Once again, with the network the black curve replaces the gray curve underneath. Whereas the benchmark model equilibria at $E_{1}$ and $E_{3}$ are unaffected by the introduction of the possibility of a network, the intermediate equilibrium at $E_{2}$ is now replaced by $E_{N}$, at which a network is formed.

This new network equilibrium points to a remarkable consequence: formation of a network reduces the fraction of type- $H$ entrepreneurs, even though the signal mechanism of the network is neither flawed nor nepotistic. ${ }^{12}$ In this setting, at $E_{2}$,

\footnotetext{
${ }^{12}$ The signal mechanism is not flawed as $x>y$ and thus the hub firm can better differentiate between type- $H$ and type- $L$ entrepreneurs than the market. It is not nepotistic, either, since the hub firm does not base its decision on anything other than merit (in this case the type of an agent).
} 


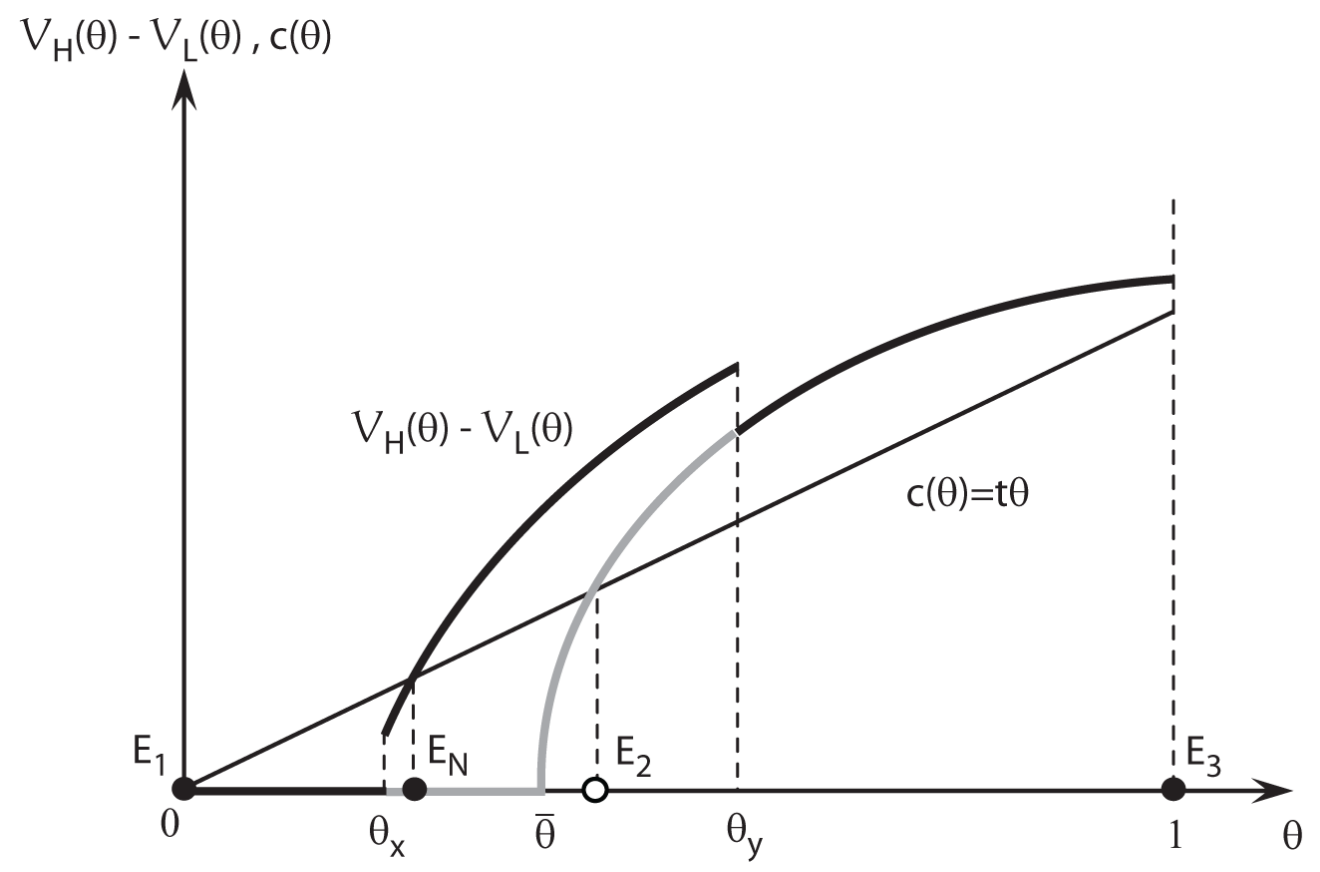

Figure 5: An equilibrium configuration when there is a network: case 2

the marginal net benefit of upgrading the project is higher than the marginal net benefit of not upgrading it (i.e., $\left.d\left[\mathcal{V}_{H}(\theta)-c(\theta)\right] / d \theta>d \mathcal{V}_{L}(\theta) / d \theta\right)$, which implies that the new marginal entrepreneur must be to the left of the original one and hence the new equilibrium occurs at a lower $\theta$. Notice also that a network forms only with $E_{N}$ in this configuration. Therefore, we conclude that introduction of a network in an economy which displays an intermediate equilibrium like $E_{2}$ in the absence of a network will reduce welfare.

Stability properties and adjustment processes around an equilibrium like $E_{N}$ are similar to those of $E_{2}$, which we discussed at the end of Section 3. There are, however, additional factors that would contribute to the persistence of an intermediate equilibrium like $E_{N}$ in the presence of a network. A trivial factor is the fact that operating the network is a profitable business for the hub firm. Given that the network forms only by the technically unstable equilibrium in the configuration shown in Figure 
5 , the hub firm can play the role of a coordination device around $E_{N}$. Joining the network is also beneficial for entrepreneurs, which will create even further incentives to fix expectations on the middle equilibrium at $E_{N}$ in Figure 5.

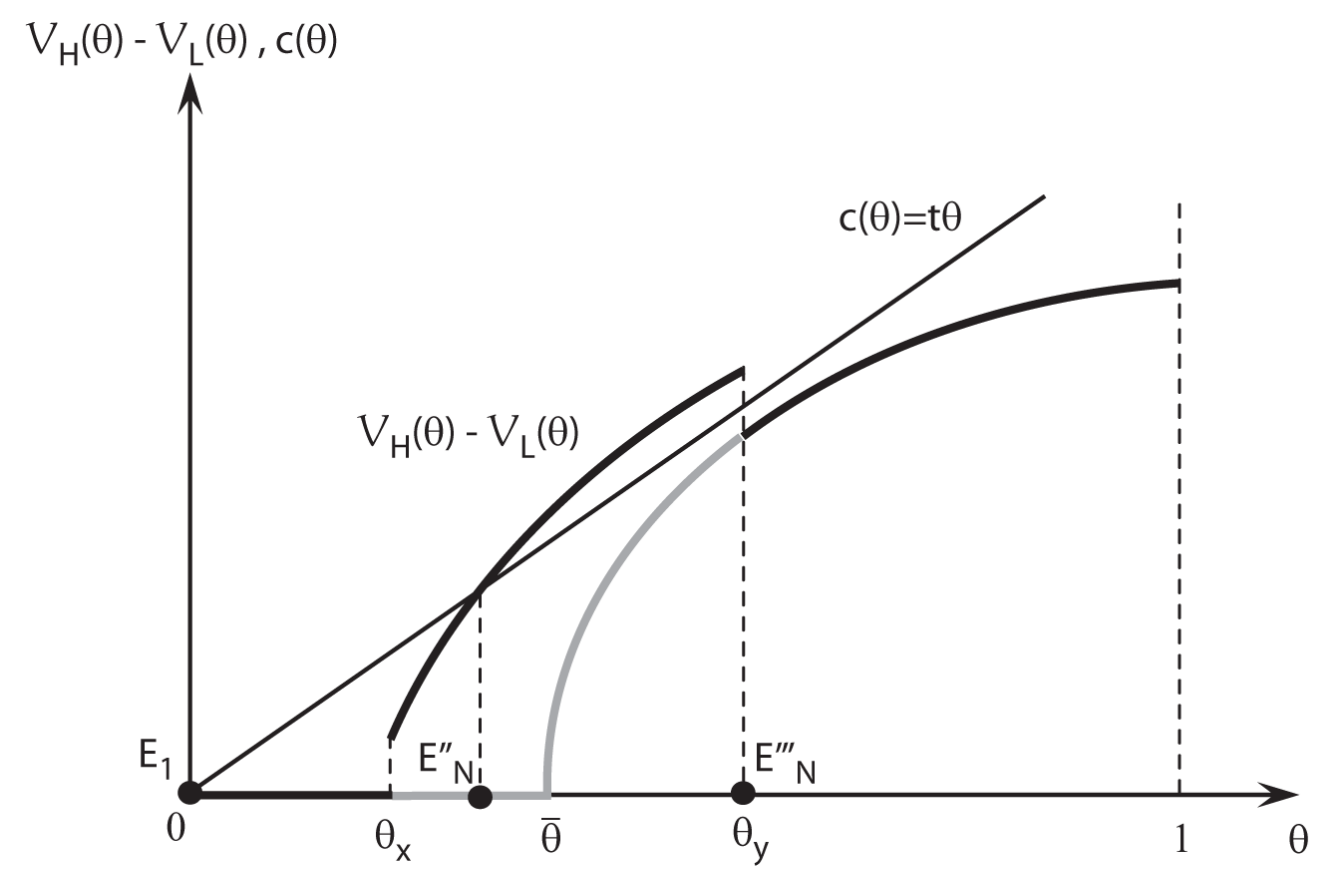

Figure 6: An equilibrium configuration when there is a network: case 3

The third equilibrium configuration is shown in Figure 6. The only equilibrium in the absence of a network occurs at $E_{1}$. Here, as in the case displayed in Figure 4, introducing the network can lead to an equilibrium with larger $\theta$. But unlike Figure 4 , it may do so with a technically stable or unstable equilibrium, denoted by $E_{N}^{\prime \prime \prime}$ and $E_{N}^{\prime \prime}$, respectively. We collect these results in the following proposition.

Proposition 4 (Equilibrium) Consider an information network that is neither nepotistic nor informationally disadvantaged.

(i) This network may have positive or negative welfare consequences, that is, increase or decrease the equilibrium number of entrepreneurs who upgrade their projects 
from inefficient ones to efficient ones.

(ii) A network that increases welfare can be technically stable or unstable but a network that decreases welfare is always technically unstable.

These results beg the question: do we need any public policy to improve an equilibrium such as $E_{N}$ ? The answer is a cautious "yes," because technically unstable network equilibria are unlikely to wither away once formed. If, as a result of an unexpected disturbance to the upgrading technology (for example, one that causes a small fraction of failures in upgrading investments) or a coordination failure, the realized measure of upgraded projects falls short of $E_{N}$, this $\theta$ value will persist because, as we argued in Section 3, upgrading costs are sunk and prospective net operation profits are positive for all type- $H$ entrepreneurs. When the realized measure of upgraded projects exceeds $E_{N}$, say, because a small measure of relatively large-cost entrepreneurs mistakenly or by a coordination failure have upgraded their projects, some stand-alone entrepreneurs will see it to their advantage to undertake the upgrading investment. But the adjustment to the new equilibrium can take a long time, or even a generation. Because the welfare decreasing effects of the network may persist, equilibria like $E_{N}$ are of interest and policy relevant.

It is well-known that many start-ups end up as failures within the first couple of years of business (see Inci, 2008 and the references cited there). Indeed, de Meza and Webb (1987), Inci (2006), and Parker (2003) showed that asymmetric information, in and of itself, may lead to a suboptimal average quality of entrepreneurs. Our result provides one explanation for how this high rate of failure can sometimes be amplified by networks. Because the networks we consider here are all meritocratic and have informational advantage over the market, the remedy to the problem depends on our ability to distinguish networks formed by $E_{N}$ from those formed by $E_{N}^{\prime}$ in reality. 


\section{Concluding remarks}

We studied a model in which entrepreneurs have the option of upgrading their types and potentially join an information network, thereby get access to better terms of borrowing. We identified cases in which introduction of a network improves welfare and increases the number of high-quality entrepreneurs and cases in which the opposite happens. The former possibility can be associated with both technically stable and unstable equilibria whereas the latter possibility is always associated with technically unstable equilibria.

While our model is useful in developing a conceptual framework for the analysis of investment incentives in efficient projects, it is too simple to capture all the functions performed by networks. For example, even though our monopoly hub model includes some features that are of interest in real life network formation cases, it fails to capture the potential effects of competition between networks. We believe it is useful to extend the model and allow for multiple hub firms to study the effects of competition in attracting entrepreneurs to each individual network (see, for example, Saloner, 1985 for a model of referees competing with each other). Such an extension can also provide insights about the effect of competition on the welfare effects of networks identified in this paper.

The Green Paper: Entrepreneurship in Europe (European Commission, 2003) points out that business networks are becoming increasingly important and proposes many policy suggestions for fostering and improving them. Industrial history is as rich in cases of successful business networks as cases of networks that rose up and declined rapidly. Future research should investigate more both in theoretical and empirical settings the practical feasibility of the idea that policies can improve the structures 
and workings of business networks. We know, on the one hand, that the information generated in the networks of entrepreneurs can mitigate the adverse selection problems for their members as long as they are not nepotistic or informationally disadvantaged, on the other hand whether they have desirable effects for the public is a question that will continue to haunt us.

\section{A Appendix}

\section{A.1 Proof of Lemma 1}

Assume instead that there is a separating equilibrium. The competition among lenders implies that they make zero profits in equilibrium. Therefore, if there were separating contracts, lenders have to make zero profits from each of these contracts. The zero-profit condition for the contract aimed at type- $i$ entrepreneurs is given by

$$
p_{i}\left(Y-B_{i}^{S}\right)-\left(1-p_{i}\right) B_{i}^{F}=(1+r) I \quad \forall i \in\{H, L\} \quad,
$$

where $B_{i}^{S}$ is the realized payoff of an entrepreneur when he is successful and $B_{i}^{F}$ is that when he fails. The corresponding iso-profit lines are given by

$$
p_{i} B_{i}^{S}+\left(1-p_{i}\right) B_{i}^{F}=\bar{B}_{i} \quad \forall i \in\{H, L\} \quad,
$$

where $\bar{B}_{i}$ is a fixed payoff level. Note that a separating contract must satisfy all four equations defined in (A-1) and (A-2). However, in the $B^{S}-B^{F}$ space, the zero profit condition with type- $i$ entrepreneurs is parallel to the iso-profit line of type- $i$ entrepreneurs. What is more is that the slopes of the lines associated with type- $H$ entrepreneurs is smaller than those of type- $L$ entrepreneurs. Therefore, given limited liability, there is no separating contract that simultaneously satisfies these four equations, which establishes a contradiction.

\section{A.2 Proof of Lemma 2}

$\bar{\theta}$ is defined by $p_{L}[Y-R(\bar{\theta}) I]=0$ where $R(\bar{\theta})=(1+r) I /\left[\bar{\theta} p_{H}+(1-\bar{\theta}) p_{L}\right]$. Hence,

$$
\bar{\theta}=\frac{(1+r) I-p_{L} Y}{\left(p_{H}-p_{L}\right) Y}
$$


$\theta_{x}$ and $\theta_{y}$ are given by (12) and (13), respectively. Once we substitute for $\pi_{H}$ and $\pi_{L}$ in these expressions, we get

$$
\begin{aligned}
\theta_{x} & =\frac{y\left[(1+r) I-p_{L} Y\right]}{x\left[p_{H} Y-(1+r) I\right]+y\left[(1+r) I-p_{L} Y\right]} \\
\theta_{y} & =\frac{(1-y)\left[(1+r) I-p_{L} Y\right]}{(1-x)\left[p_{H} Y-(1+r) I\right]+(1-y)\left[(1+r) I-p_{L} Y\right]} .
\end{aligned}
$$

Therefore, $\bar{\theta}>\theta_{x}$ if

$$
\frac{(1+r) I-p_{L} Y}{\left(p_{H}-p_{L}\right) Y}>\frac{y\left[(1+r) I-p_{L} Y\right]}{x\left[p_{H} Y-(1+r) I\right]+y\left[(1+r) I-p_{L} Y\right]} .
$$

Hence,

$$
\begin{aligned}
x p_{H} Y-y p_{L} Y-(x-y)(1+r) I & >y p_{H} Y-y p_{L} Y \\
(x-y) p_{H} Y & >(x-y)(1+r) I \\
p_{H} Y & >(1+r) I .
\end{aligned}
$$

This always holds by Assumption 1. Similarly, $\bar{\theta}<\theta_{y}$ if

$$
\frac{(1+r) I-p_{L} Y}{\left(p_{H}-p_{L}\right) Y}<\frac{(1-y)\left[(1+r) I-p_{L} Y\right]}{(1-x)\left[p_{H} Y-(1+r) I\right]+(1-y)\left[(1+r) I-p_{L} Y\right]} .
$$

Hence,

$$
\begin{aligned}
(1-x) p_{H} Y-(1-x)(1+r) I+(1-y) & (1+r) I<p_{H}(1-y) Y \\
(x-y) & (1+r) I<(x-y) p_{H} Y \\
(1+r) I & <p_{H} Y .
\end{aligned}
$$

Once again, this always holds by Assumption 1.

\section{A.3 Alternative objectives of a network organizer}

The network organizer in this paper is an established firm but we could have other interpretations. For example, the organizer can be a mutual guarantee scheme, a credit guarantee fund (both of which are formal rather than informal), or even a group of individuals or firms (see Parker, 2004, pp. 169-171 for a discussion of such institutions in entrepreneurship). In all of these interpretations, the organizer admits members to maximize its benefit, no matter whether this is pecuniary or non-pecuniary.

Alternative interpretations may be employed with slight modifications of the model. For instance, a mutual guarantee scheme usually takes fixed fees and use collected funds as collateral when a member applies for credit. The background assumption here is that members involve in peer screening during group formation and that assortative matching is possible, just like in micro-credit group lending schemes. In the present model, the fact 
that the hub firm takes an equity share of the start-up has the same background role. In particular, the hub firm finances its portion of share from its own resources, which it would not do if it thinks that the project is not worth investing.

In our model, ex ante all entrepreneurs have the chance to become a network member and the possibility of network membership in the future affects entrepreneurs' upgrade decisions today. In the end, only some realize membership. While the network owner in our model seeks to maximize its own profits, in practice networks may be formed by a group of people who aim to maximize their welfare or there could be a fixed group that forms the network ex ante. Below, we briefly discuss and relate network types to their organizers and expected outcomes.

1. A hub firm maximizing the total welfare of network entrepreneurs.

Suppose that, given $\theta$, the hub firm makes its decision based on expected values of the network firms rather than taking an $\alpha$ share and self financing that portion. It turns out that this modification leaves unchanged the critical values of the ratio of type- $H$ entrepreneurs, $\theta_{x}$ and $\theta_{y}$, for a good signal and a bad signal, respectively.

By making use of (9) and (10), we can find the hub firm's expected payoff from acceptance as a function of the signal:

$$
\Pi^{J}(\theta)=J(\theta) p_{H}\left(Y-R^{N}(\theta) I\right)+(1-J(\theta)) p_{L}\left(Y-R^{N}(\theta) I\right) \quad \forall J \in\{G, B\} \quad .
$$

Manipulating this yields

$$
\left[J(\theta) p_{H}+(1-J(\theta)) p_{L}\right] Y-(1+r) I \quad \forall J \in\{G, B\} \quad .
$$

The hub firm is indifferent between accepting an entrepreneur with a good signal to the network and rejecting him when $\Pi^{G}\left(\theta_{x}\right)=0$. Then,

$$
\begin{aligned}
{\left[G\left(\theta_{x}\right) p_{H}+\left(1-G\left(\theta_{x}\right)\right) p_{L}\right] Y-(1+r) I } & =0 \\
\left(\frac{x \theta_{x} p_{H}+y\left(1-\theta_{x}\right) p_{L}}{x \theta_{x}+y\left(1-\theta_{x}\right)}\right) Y & =(1+r) I \\
{\left[x \theta_{x} p_{H}+y\left(1-\theta_{x}\right) p_{L}\right] Y } & =\left(x \theta_{x}+y\left(1-\theta_{x}\right)\right)(1+r) I \\
{\left[x p_{H} Y-x(1+r) I-y p_{L} Y+(1+r) I y\right] \theta_{x} } & =(1+r) I y-y p_{L} Y .
\end{aligned}
$$

Manipulating this yields

$$
\left[x\left(p_{H} Y-(1+r) I\right)-y\left(p_{L} Y+(1+r) I\right)\right] \theta_{x}=-y\left(p_{L} Y-(1+r) I\right)
$$

from which we get exactly the same condition given in (12). Similarly, we can define a critical $\theta_{y}$ for the case of a bad signal through $\Pi^{B}\left(\theta_{y}\right)=0$, and going through similar algebraic manipulations above we get once again the same condition in (13). Thus, our results remain unchanged even when the hub firm is concerned about the total welfare of its members. This is not surprising because the profit share $\alpha$ enters into equations in a multiplicative fashion and thus the preferences of the network members and the hub firm 
stay in line with each other.

2. A network is founded by a group of entrepreneurs with low costs of project upgrading.

Assume that low-cost types (i.e., those with lower $c$ values) through some exogenous process, are able to form a network. These entrepreneurs could be well-educated high-skilled individuals who are acting together. Let the critical cost threshold under which the network forms is given by $n$ (call this the network threshold). Then, by the uniform distribution assumption, we would have a mass $n / t$ of network members. There are two cases to consider here.

In the first case, the critical network threshold is lower than the critical cost threshold under which all individuals prefer becoming type- $H$ entrepreneurs (i.e., $n<c$ ). Now that all network entrepreneurs are type- $H$ entrepreneurs, they will all be offered efficient lending contracts. Among the remaining population, there will be only $(c-n) / t$ type- $H$ entrepreneurs along with $(t-c) / t$ type- $L$ entrepreneurs. If the number of type- $H$ entrepreneurs is sufficiently large in this population, these entrepreneurs will get fully-pooling contracts and otherwise semi-pooling contracts.

In the second case, $n>c$ and thus the network includes $c / t$ type- $H$ and $(n-c) / t$ type- $L$ entrepreneurs. These network entrepreneurs will be given lending contracts consistent with their average risk. The stand-alone population, on the other hand, is composed of all type- $L$ entrepreneurs, which means that they will not be offered any credit since their projects are inefficient. Hence, all financed projects will belong to the network members. The crucial point is that the network is still composed of both type- $H$ and type- $L$ entrepreneurs.

3. A network is founded by a group of entrepreneurs with high costs of project upgrading.

Suppose, now, that high-cost types (i.e., those with higher $c$ values) are able to form a network. For example, this network could be located in an underdeveloped region of the country. Let, once again, the critical cost threshold under which the network forms be $n$ (call this the network threshold). We would have a mass $(t-n) / t$ of network members. Once again, there are two cases to consider.

If the critical network threshold is lower than the critical cost threshold under which all individuals prefer becoming type- $H$ entrepreneurs $(i . e ., n<c$ ), all stand-alone entrepreneurs will be type- $H$ entrepreneurs. Given this, these entrepreneurs will be offered efficient lending contracts. On the other hand, network entrepreneurs will be composed of $(c-n) / t$ type- $H$ entrepreneurs and $(t-c) / t$ type- $L$ entrepreneurs. If the number of type- $H$ entrepreneurs is sufficiently large in this population, these entrepreneurs will get fully-pooling contracts and otherwise semi-pooling contracts. Note, however, given that the stand-alone entrepreneurs are getting cheaper finance, these network entrepreneurs will prefer to leave the network.

Who leaves the network first might change the end result. If, for example, a sufficiently large number of type- $L$ entrepreneurs leave the network first, then the loan prices may get equalized in and outside the network. In this case, we end up with a heterogenous network 
once again. If, on the other hand, type- $H$ entrepreneurs leave the network first, then the network will include only type- $L$ entrepreneurs, which means that it will collapse.

In the second case, $n>c$ and thus the network is composed of all type- $L$ entrepreneurs, which means that they would not be given credit. Once again, in this case, network entrepreneurs prefer becoming stand-alone entrepreneurs and thus we cannot have such a network in equilibrium.

\section{References}

[1] Aldrich, H., B. Rosen and W. Woodward, 1987, "The Impact of Social Networks on Business Foundings and Profit: A Longitudinal Study," N. Churchill, J. Hornaday, O. Krasner and K. Vesper, eds. Frontiers of Entrepreneurship Research, Wellesley, MA: Babson College, 154-168.

[2] Aldrich, H. and C. Zimmer, 1986, "Entrepreneurship Through Social Networks," D. Sexton and R. Smilor, eds. The Art and Science of Entrepreneurship, Ballinger.

[3] Aldrich, H. and P. Kim, 2007, "Small Worlds, Infinite Possibilities? How Social Networks Affect Entrepreneurial Team Formation and Search," Strategic Entrepreneurship Journal, 1, 147-165.

[4] Biggs, T. and M. Shah, 2006, "African SMES, Networks, and Manufacturing Performance," Journal of Banking \& Finance, 30, 3043-3066.

[5] Birley, S., 1985, "The Role of Networks in the Entrepreneurial Process," Journal of Business Venturing, 1, 107-117.

[6] Bruderl, J. and P. Preisendorfer, 1998, "Network Support and the Success of Newly Founded Businesses," Small Business Economics, 10, 213-225.

[7] Cahuc, P and F. Fontaine, 2009, "On the Efficiency of Job Search with Social Networks," Journal of Public Economic Theory, 11, 411-439.

[8] Calvo-Armengol, A. and M. Jackson, 2004, "The Effects of Social Networks on Employment and Inequality," American Economic Review, 94, 27-46.

[9] Calvo-Armengol, A. and M. Jackson, 2007, "Networks in Labor Markets: Wage and Employment Dynamics and Inequality," Journal of Economic Theory, 132, 426-454.

[10] Calvo-Armengol, A. and Y. Zenou, 2005, "Job Matching, Social Network and Wordof-mouth Communication," Journal of Urban Economics, 57, 500-522.

[11] Crawford, V. and J. Sobel, 1982, "Strategic Information Transmission," Econometrica, $50,1431-1451$.

[12] de Meza, D. and D. Webb, 1987, "Too Much Investment: A Problem of Asymmetric Information," Quarterly Journal of Economics, 102, 281-292. 
[13] Dubini, P. and H. Aldrich, 1991, "Personal and Extended Networks are Central to the Entrepreneurial Process," Journal of Business Venturing, 6, 305-313.

[14] European Commission, 2003, Green Paper: Entrepreneurship in Europe. Brussels.

[15] Fontaine, F., 2007, "A simple Matching Model with Social Networks," Economics Letters, 94, 396-401.

[16] Granovetter, M., 1974, Getting a Job: A Study of Contacts and Careers. Cambridge, MA: Harvard University Press.

[17] Harsanyi, J. and R. Selten, 1972, "A Generalized Nash Bargaining Solution for Twoperson Bargaining Games with Incomplete Information," Management Science, 18, P80-P106.

[18] Holzer, H., 1988, "Search Method Use by Unemployed Youth," Journal of Labor Economics, 6, 1-20.

[19] Inci, E., 2006, "Occupational Choice and the Quality of Entrepreneurs," Boston College Working Paper, 666.

[20] Inci, E., 2008. "Success Breeds Success Only Locally: A Tale of Cherry-Picker Networks," Sabanci University Working Paper.

[21] Ioannides, Y. and L. Loury, 2004, "Job Information Networks, Neighborhood Effects, and Inequality," Journal of Economic Literature, 42, 1056-1093.

[22] Kono, H., 2006, "Employment with Connections: Negative Network Effects," Journal of Development Economics, 81, 244-258.

[23] Kugler, A., 2003, "Employee Referrals and Efficiency Wages," Labour Economics, 10, $531-556$.

[24] Lamoreaux, N., M. Levenstein and K. Sokoloff, 2007, "Financing Invention During the Second Industrial Revolution: Cleveland, Ohio, 1870-1920," N. Lamoreaux, K. Sokoloff, Eds., Financing Innovation in the United States, 1870 to Present, Cambridge: MIT Press.

[25] Lentz, B. and D. Laband, 1989, "Why So Many Children of Doctors Become Doctors: Nepotism vs. Human Capital Transfers," Journal of Human Resources, 24, 396-413.

[26] Montgomery, J., 1991, "Social Networks and Labor-market Outcomes: Toward an Economic Analysis," American Economic Review, 81, 1408-1418.

[27] Mortensen, D. and T. Vishwanath, 1994, "Personal Contacts and Earnings: It is Who You Know!," Labour Economics, 1, 187-201.

[28] Munshi, K., 2003, "Networks in the Modern Economy: Mexican Migrants in the US Labor Market," Quarterly Journal of Economics, 118, 549-599. 
[29] Parker, S., 2003, "Asymmetric Information, Occupational Choice and Government Policy," Economic Journal, 113, 861-882.

[30] Parker, S., 2004, The Economics of Self-Employment and Entrepreneurship, Cambridge: Cambridge University Press.

[31] Parker, S., 2008, "The Economics of Formal Business Networks," Journal of Business Venturing, 23, 627-640.

[32] Petersen, M. and R. Rajan,1994, "The Benefits of Lending Relationships: Evidence from Small Business Data", Journal of Finance, 49, 3-37.

[33] Rees, A., 1966, "Information Networks in Labor Markets," American Economic Review Papers and Proceedings, 56, 559-566.

[34] Russo, P. and P. Rossi, 2001, "Credit Constraints in Italian Industrial Districts", Applied Economics, 33, 1469-1477.

[35] Saloner, G., 1985, "Old Boy Networks as Screening Mechanisms," Journal of Labor Economics, 3, 255-267.

[36] Simon, J. and J. Warner, 1992, "Matchmaker, Matchmaker: The Effect of Old Boy Networks on Job Match Quality, Earnings, and Tenure," Journal of Labor Economics, 10, 306-330.

[37] Taylor, C., 2000, "The Old-boy Network and the Young-gun Effect," International Economic Review, 41, 871-891.

[38] Uzzi, B., 1999, "Embeddedness in the Making of Financial Capital: How Social Relations and Networks Benefit Firms Seeking Financing," American Sociological Review, 64, 481-505.

[39] Uzzi, B. and R. Lancaster, 2003, "Relational Embeddedness and Learning: The Case of Bank Loan Managers and Their Clients," Management Science, 49, 383-399.

[40] Wabha, J. and Y. Zenou, 2005, "Density, Social Networks and Job Search Methods: Theory and Application to Egypt," Journal of Development Economics, 88, 443-473. 


\section{CESifo Working Paper Series}

for full list see www.cesifo-group.org/wp

(address: Poschingerstr. 5, 81679 Munich, Germany, office@cesifo.de)

3005 Jay Pil Choi and Heiko Gerlach, Global Cartels, Leniency Programs and International Antitrust Cooperation, March 2010

3006 Aneta Hryckiewicz and Oskar Kowalewski, Why do Foreign Banks Withdraw from other Countries? A Panel Data Analysis, March 2010

3007 Eric A. Hanushek and Ludger Woessmann, Sample Selectivity and the Validity of International Student Achievement Tests in Economic Research, March 2010

3008 Dennis Novy, International Trade and Monopolistic Competition without CES: Estimating Translog Gravity, April 2010

3009 Yin-Wong Cheung, Guonan Ma and Robert N. McCauley, Renminbising China's Foreign Assets, April 2010

3010 Michel Beine and Sara Salomone, Migration and Networks: Does Education Matter more than Gender?, April 2010

3011 Friedrich Schneider, Tilman Brück and Daniel Meierrieks, The Economics of Terrorism and Counter-Terrorism: A Survey (Part I), April 2010

3012 Friedrich Schneider, Tilman Brück and Daniel Meierrieks, The Economics of Terrorism and Counter-Terrorism: A Survey (Part II), April 2010

3013 Frederick van der Ploeg and Steven Poelhekke, The Pungent Smell of "Red Herrings": Subsoil Assets, Rents, Volatility and the Resource Curse, April 2010

3014 Vjollca Sadiraj, Jan Tuinstra and Frans van Winden, Identification of Voters with Interest Groups Improves the Electoral Chances of the Challenger, April 2010

3015 Guglielmo Maria Caporale, Davide Ciferri and Alessandro Girardi, Time-Varying Spot and Futures Oil Price Dynamics, April 2010

3016 Scott Alan Carson, Racial Differences in Body-Mass Indices for Men Imprisoned in $19^{\text {th }}$ Century US Prisons: A Multinomial Approach, April 2010

3017 Alessandro Fedele, Paolo M. Panteghini and Sergio Vergalli, Optimal Investment and Financial Strategies under Tax Rate Uncertainty, April 2010

3018 Laurence Jacquet, Take it or Leave it: Take-up, Optimal Transfer Programs, and Monitoring, April 2010

3019 Wilhelm Kohler and Jens Wrona, Offshoring Tasks, yet Creating Jobs?, April 2010

3020 Paul De Grauwe, Top-Down versus Bottom-Up Macroeconomics, April 2010 
3021 Karl Ove Aarbu, Demand Patterns for Treatment Insurance in Norway, April 2010

3022 Toke S. Aidt and Jayasri Dutta, Fiscal Federalism and Electoral Accountability, April 2010

3023 Bahram Pesaran and M. Hashem Pesaran, Conditional Volatility and Correlations of Weekly Returns and the VaR Analysis of 2008 Stock Market Crash, April 2010

3024 Stefan Buehler and Dennis L. Gärtner, Making Sense of Non-Binding Retail-Price Recommendations, April 2010

3025 Leonid V. Azarnert, Immigration, Fertility, and Human Capital: A Model of Economic Decline of the West, April 2010

3026 Christian Bayer and Klaus Wälde, Matching and Saving in Continuous Time: Theory and 3026-A Matching and Saving in Continuous Time: Proofs, April 2010

3027 Coen N. Teulings and Nick Zubanov, Is Economic Recovery a Myth? Robust Estimation of Impulse Responses, April 2010

3028 Clara Graziano and Annalisa Luporini, Optimal Delegation when the Large Shareholder has Multiple Tasks, April 2010

3029 Erik Snowberg and Justin Wolfers, Explaining the Favorite-Longshot Bias: Is it RiskLove or Misperceptions?, April 2010

3030 Doina Radulescu, The Effects of a Bonus Tax on Manager Compensation and Welfare, April 2010

3031 Helmut Lütkepohl, Forecasting Nonlinear Aggregates and Aggregates with Timevarying Weights, April 2010

3032 Silvia Rocha-Akis and Ronnie Schöb, Welfare Policy in the Presence of Unionised Labour and Internationally Mobile Firms, April 2010

3033 Steven Brakman, Robert Inklaar and Charles van Marrewijk, Structural Change in OECD Comparative Advantage, April 2010

3034 Dirk Schindler and Guttorm Schjelderup, Multinationals, Minority Ownership and TaxEfficient Financing Structures, April 2010

3035 Christian Lessmann and Gunther Markwardt, Decentralization and Foreign Aid Effectiveness: Do Aid Modality and Federal Design Matter in Poverty Alleviation?, April 2010

3036 Eva Deuchert and Conny Wunsch, Evaluating Nationwide Health Interventions when Standard Before-After Doesn't Work: Malawi's ITN Distribution Program, April 2010

3037 Eric A. Hanushek and Ludger Woessmann, The Economics of International Differences in Educational Achievement, April 2010 
3038 Frederick van der Ploeg, Aggressive Oil Extraction and Precautionary Saving: Coping with Volatility, April 2010

3039 Ainura Uzagalieva, Evžen Kočenda and Antonio Menezes, Technological Imitation and Innovation in New European Union Markets, April 2010

3040 Nicolas Sauter, Jan Walliser and Joachim Winter, Tax Incentives, Bequest Motives, and the Demand for Life Insurance: Evidence from two Natural Experiments in Germany, April 2010

3041 Matthias Wrede, Multinational Capital Structure and Tax Competition, April 2010

3042 Burkhard Heer and Alfred Maussner, A Note on the Computation of the Equity Premium and the Market Value of Firm Equity, April 2010

3043 Kristiina Huttunen, Jukka Pirttilä and Roope Uusitalo, The Employment Effects of Low-Wage Subsidies, May 2010

3044 Matthias Kalkuhl and Ottmar Edenhofer, Prices vs. Quantities and the Intertemporal Dynamics of the Climate Rent, May 2010

3045 Bruno S. Frey and Lasse Steiner, Pay as you Go: A New Proposal for Museum Pricing, May 2010

3046 Henning Bohn and Charles Stuart, Population under a Cap on Greenhouse Gas Emissions, May 2010

3047 Balázs Égert and Rafal Kierzenkowski, Exports and Property Prices in France: Are they Connected?, May 2010

3048 Thomas Eichner and Thorsten Upmann, Tax-Competition with Involuntary Unemployment, May 2010

3049 Taiji Furusawa, Kazumi Hori and Ian Wooton, A Race beyond the Bottom: The Nature of Bidding for a Firm, May 2010

3050 Xavier Vives, Competition and Stability in Banking, May 2010

3051 Thomas Aronsson and Erkki Koskela, Redistributive Income Taxation under Outsourcing and Foreign Direct Investment, May 2010

3052 Michael Melvin and Duncan Shand, Active Currency Investing and Performance Benchmarks, May 2010

3053 Sören Blomquist and Laurent Simula, Marginal Deadweight Loss when the Income Tax is Nonlinear, May 2010

3054 Lukas Menkhoff, Carol L. Osler and Maik Schmeling, Limit-Order Submission Strategies under Asymmetric Information, May 2010 
3055 M. Hashem Pesaran and Alexander Chudik, Econometric Analysis of High Dimensional VARs Featuring a Dominant Unit, May 2010

3056 Rabah Arezki and Frederick van der Ploeg, Do Natural Resources Depress Income Per Capita?, May 2010

3057 Joseph Plasmans and Ruslan Lukach, The Patterns of Inter-firm and Inter-industry Knowledge Flows in the Netherlands, May 2010

3058 Jenny E. Ligthart and Sebastian E. V. Werner, Has the Euro Affected the Choice of Invoicing Currency?, May 2010

3059 Håkan Selin, Marginal Tax Rates and Tax-Favoured Pension Savings of the SelfEmployed - Evidence from Sweden, May 2010

3060 Richard Cornes, Roger Hartley and Yuji Tamura, A New Approach to Solving Production-Appropriation Games with Many Heterogeneous Players, May 2010

3061 Ronald MacDonald and Flávio Vieira, A Panel Data Investigation of Real Exchange Rate Misalignment and Growth, May 2010

3062 Thomas Eichner and Rüdiger Pethig, Efficient Management of Insecure Fossil Fuel Imports through Taxing(!) Domestic Green Energy?, May 2010

3063 Vít Bubák, Evžen Kočenda and Filip Žikeš, Volatility Transmission in Emerging European Foreign Exchange Markets, May 2010

3064 Leonid V. Azarnert, Après nous le Déluge: Fertility and the Intensity of Struggle against Immigration, May 2010

3065 William E. Becker, William H. Greene and John J. Siegfried, Do Undergraduate Majors or Ph.D. Students Affect Faculty Size?, May 2010

3066 Johannes Becker, Strategic Trade Policy through the Tax System, May 2010

3067 Omer Biran and Françoise Forges, Core-stable Rings in Auctions with Independent Private Values, May 2010

3068 Torben M. Andersen, Why do Scandinavians Work?, May 2010

3069 Andrey Launov and Klaus Wälde, Estimating Incentive and Welfare Effects of NonStationary Unemployment Benefits, May 2010

3070 Simon Gächter, Benedikt Herrmann and Christian Thöni, Culture and Cooperation, June 2010

3071 Mehmet Bac and Eren Inci, The Old-Boy Network and the Quality of Entrepreneurs, June 2010 